\title{
Donación del neófito zaragozano Juan Çeal a su hijo Francés de una casa «clamada sinoga» en 1417
}

\author{
Encarnación MARÍN PADILLA \\ CSIC, Madrid
}

Hace cuatro años daba noticia de una sinagoga desconocida de Zaragoza, la de «Alhaquim» ${ }^{1}$. En esta ocasión voy a referirme a un instrumento público notarial de 1417 en el que se alude a una casa «clamada sinoga», con «atoras, coronas e pomas de argent», propiedad del neófito zaragozano Juan Çeal o Çial.

Encontré el citado documento, una donación, en el Registro y Protocolo correspondientes a dicho año del notario Pedro Serrano, en una de mis frecuentes estancias en el Archivo de Protocolos Notariales de la ciudad aragonesa ${ }^{2}$.

El motivo de que el neófito zaragozano Juan Çeal compareciera ante notario para donar a su hijo Francés Çeal una casa «clamada sinoga», no fue otro, según él mismo manifestó, que el considerar los «muytos e agradables servicios, hondras e merecimientos buenos» que este le había hecho en tiempos pasados, que a diario no cesaba de hacerle y que confiaba siguiera haciéndole en el futuro.

Por esa razón y después de hacer constar que actuaba «non forçado, falagado, sedueyto, decebido ni enganyado ni por otro miedo o error indueyto ante queriendo seyer conoxient», Juan decidió compensar a su hijo Francés el viernes 17 de diciembre de

${ }^{1}$ Cf. mi artículo «Notas sobre una sinagoga de Zaragoza, la de "Alhaquim"», Sefarad 56 (1996) págs. 437-438.

${ }^{2}$ Siglas Z.APN. 
1417, en Zaragoza. Ese día Juan dio, cedió «e luego de present livro» e hizo «cession e donaçion pura, perffecta e yrrevocable entre vivos feyta», a su hijo Francés de una casa suya «clamada sinoga con todos los dreytos pertenescientes e pertenescer podientes e devientes ad aquella e con todas las atoras, coronas e pomas de argent en aquella stantes». Estaba situada «la casa, si quiere sinoga», «en barrio nuevo en el calliço clamado de Medio de la juderia» y lindaba con casas de Acach Gallur, con las de Jento Curriz, con las de Çaçon Taboch y con callizos públicos por dos partes. En la donación estaba incluido todo el «dreyto, poder, dominio e senyorio» que Juan tenía en la casa llamada sinagoga «e en los dreytos ad aquella pertenescientes e en las atoras, coronas e pomas de argent en aquella stantes». Después de especificar todo tipo de garantías sobre la donación, «et a mayor firmeza e seguridat» de Francés y de los suyos, Juan dio «fiança e salvo de la dita donacion segunt fuero de Aragon» a su convecino, el también neófito Ramón de Santa Caterina, que estaba presente, aceptó y obligó su persona y bienes, muebles e inmuebles ${ }^{3}$.

En la documentación sobre conversos recogida en mis largos años de investigación no he encontrado referencia alguna al néofito donante ni al apellido que recibió tras su bautismo. Lo que si puede afirmarse es que la casa «clamada sinoga», con «atoras, coronas e pomas de argent», era propiedad privada de Juan Çeal. Dispuso de ella y de su contenido particular y libremente; era neófito pero dado el inmueble de que se trataba, su situación y la pérdida que podría suponer para la aljama, la realidad fue que ningún oficial de esta asistió al acto, dio su consentimiento o intervino de modo alguno ${ }^{4}$.

La casa «clamada sinoga» donada por Juan Çeal a su hijo pudo ser la «sinoga clamada de Çehan» y Çehan el apellido judío del neófito Juan Çeal ${ }^{5}$. También el inmueble donado pudo ser «la

${ }^{3}$ Z.APN., Pedro Serrano, Registro y Protocolo 1417, fols. $91 \mathrm{v}-93$ y $147 \mathrm{v}$, respectivamente.

${ }^{4}$ Cuando en 1433 se vendió una parte de la sinagoga de Alhaquim fue necesario que «toda la aljama» de los judíos de Zaragoza «e concello de aquella» nombrara siete diputados que, junto con los adelantados, actuaron como vendedores de parte del inmueble.

${ }^{5}$ En 1407 la «sinoga clamada de Çehan» estaba situada en la parroquia de San Miguel de los Navarros, en el callizo «clamado de medio de la sinoga del Cosso de la juderia» y lindaba con casas que ocupaba Acach Gallur (Z.APN., Fernando 
sinoga questa cerrada», citada en un documento fechado en 1429 , sin que se especifique el barrio en que se encontraba ${ }^{6}$.

\section{RESUMEN}

La autora da noticia de un documento del Archivo de Protocolos Notariales de Zaragoza, que testificó el notario de la ciudad Pedro Serrano en 1417. Se alude en el mismo a la donación que hizo el neófito zaragozano Juan Çeal o Çial a su hijo Francés de una casa «clamada sinoga», con «atoras, coronas e pomas de argent».

\section{SUMMARY}

The author of thr present study brings to light a document discovered in the Zaragoza Notarial Protocol Archives. It was witnessed by the municipal notary Pedro Serrano in 1417. This document includes an allusion to a donation of a house that the recently baptized Zaragozan Juan Çeal or Çial had made to his son Frances. This property, called sinoga, contained Torahs and rimonim.

Pérez de Samper, 1407, fol. 7v). El documento lo ha publicado M. SERRANO Y SANZ en el apéndice de "Capitulaciones para el arriendo de la sisa del vino de la judería de Zaragoza, desde el 26 de septiembre de 1464 a igual fecha de 1465 », en Memorias de la Facultad de F. y L. de Zaragoza (1922-1923) págs. 356-365, y a él se han referido otros autores.

${ }^{6}$ Esta «sinoga questa cerrada» lindaba con unas casas de la judería propiedad de Martín de Marcuello que a su vez lo hacían con casas de Bitas Adich, con las de Sento Gallur, con las del converso Fernando de la Caballería y con carrera pública (Z.APN., Pedro Serrano, Protocolo 1429, fol. 123). 